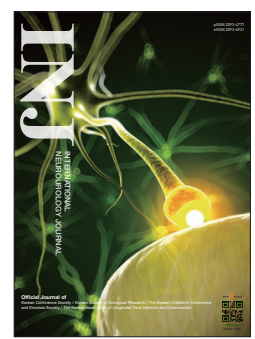

\title{
Radiographic Position of the Electrode as a Predictor of the Outcome of InterStim Therapy
}

\author{
Abdullah Ahmed Gahzi ${ }^{1}$, Mai Ahmed Banakhar ${ }^{2}$, Dean S. Elterman ${ }^{3}$, Magdy Hassouna ${ }^{1}$ \\ ${ }^{1}$ Toronto Western Hospital, Toronto, ON, Canada \\ ${ }^{2}$ King Abdulaziz University, Jeddah, Saudi Arabia \\ ${ }^{3}$ Toronto Western Hospital, Toronto, ON, Canada
}

Purpose: Sacral neuromodulation (SNM) therapy is indicated for some refractory urological conditions. The electrode lead position in sacral $\mathrm{x}$-rays during routine follow-up may predict the outcome of SNM therapy. To determine whether the radiographic position of the electrode in the sacral foramen predicted the long-term outcome of SNM therapy.

Methods: This was a retrospective study of patients who underwent InterStim SNM at Toronto Western Hospital by 2 surgeons from July 2013 to March 2014. The position of electrodes in relation to the sacral bone was assessed on follow-up sacral $\mathrm{x}$-rays. In the lateral view, we determined the location of the radio-opaque marker of the electrode relative to the inner surface of the sacrum (P3, D3, P2, D2, P1, D1, P0, and D0). In the anteroposterior view, the angle between a line through the spinous process shadow and the electrode was measured $\left(0^{\circ}-30^{\circ}, 30^{\circ}-60^{\circ}, 60^{\circ}-90^{\circ},>90^{\circ}\right.$, or medial). Dissatisfied patients were defined as those who did not improve based on a voiding diary or those who needed salvage treatment after SNM. The primary endpoint was to determine whether the electrode lead position on sacral x-rays predicted the outcome of SNM therapy.

Results: A total of 69 patients ( 61 female and 8 male patients) were included, with a median age of 55 years. Forty-two of the patients $(60.9 \%)$ had refractory overactive bladder, 21 (30.4\%) suffered from chronic urinary retention, and $6(8.7 \%)$ had lower urinary tract symptoms and chronic pelvic pain syndrome. The univariate analysis did not show any correlation between SNM response and the electrode position or angle. Dummy regression analysis using response to implantation as the dependent outcome variable did not show any significance for any of the predictors.

Conclusions: Our study did not show a correlation between the long-term response to SNM and the electrode position on follow-up sacral x-rays. In this study, electrode lead position in sacral x-ray at follow-up was not correlated with the outcome of SNM therapy.

Keywords: Sacral Neuromodulation; Urinary Bladder, Overactive; Urinary Incontinence; Urinary Retention

- Research Ethics: This study was approved by the Research Ethic Board of the University Health Network (approval number: 15-9808-AE)

Written informed consent was obtained from each participant.

- Conflict of Interest: No potential conflict of interest relevant to this article was reported.

\section{INTRODUCTION}

Sacral neuromodulation (SNM) was introduced in the 1980s as a treatment for chronic voiding dysfunction [1]. SNM is a use- ful alternative therapy for a variety of refractory voiding conditions after failure of conservative and medical therapy [2]. In 1997, the U.S. Food and Drug Administration approved SNM for urgency incontinence, and in 1999 for refractory urgency-

Corresponding author: Magdy Hassouna (iD https://orcid.org/0000-0002-1096-3391 Toronto Western Hospital, 399 Bathurst St, Toronto, ON, Canada E-mail: Magdy.Hassouna@uhn.ca / Tel: +1-416 603 5018 / Fax +1-4166031961 Submitted: June 13, 2017 / Accepted after revision: November 13, 2017

(5) This is an Open Access article distributed under the terms of the Creative Commons Attribution Non-Commercial License (http://creativecommons.org/licenses/by-nc/4.0/) which permits unrestricted non-commercial use, distribution, and reproduction in any medium, provided the original work is properly cited. 
frequency syndrome and nonobstructive chronic urinary retention $[3,4]$. SNM has also shown benefits to patients suffering from fecal incontinence, chronic constipation, and chronic pelvic pain (CPP) syndrome [2,5].

The overall prevalence of overactive bladder $(\mathrm{OAB})$ in the Canadian population is estimated to be $18.1 \%$, with the prevalence lower in men (14.8\%) than in women (21.2\%) [6]. Various treatment options are available for $\mathrm{OAB}$, including lifestyle or behavioral changes, such as pelvic floor strengthening, bladder retraining, and management of daily fluid intake. Oral medications include anticholinergic (antimuscarinic) agents and a $\beta 3$ agonist [7-10].

For those individuals who are refractory to medications, intravesical botulinum toxin A injections and SNM have shown significant positive effects in controlling $\mathrm{OAB}$ symptoms, including urgency incontinence [11].

SNM is safe and effective in OAB patients, with reported rates of success ranging between $50 \%$ and $90 \%$ [12-16]. SNM improved quality of life metrics in $86 \%$ of patients [12].

SNM therapy has a modestly high rate of complications, reaching up to $18.2 \%$. Most complications are related to lead migration (11.8\%) [7].

A quadripolar permanent electrode is usually placed under fluoroscopic guidance. Once it is inserted into the S3 foramen using a specialized foramen needle, followed by a guide wire and foramen dilator, it is tested in all 4 electrode positions $(0,1$, 2 , and 3) for a response [17]. The intraoperative insertion of the electrode into the sacral foramen using a curved stylet has been shown to achieve motor responses at lower amplitudes. This could maximize the battery life and facilitate improved programming [18].
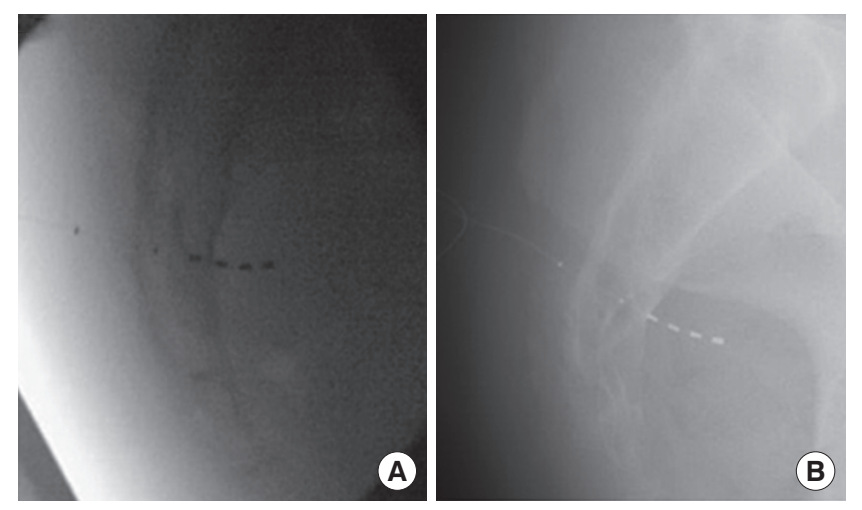

Fig. 1. Change in electrode position. (A) At the time of insertion. (B) Six months postoperatively.
Intraoperative electrode positioning has previously been described, although to our knowledge this is the first study to examine follow-up radiographic positioning of the electrode with respect to clinical outcomes. Clinically, in some instances we have noted changes in electrode positioning over time between the intraoperative and follow-up x-rays (Fig. 1).

This study aimed to determine whether the radiographic location of the tined leads on follow-up sacral $\mathrm{x}$-rays predicted the long-term outcomes of SNM therapy.

\section{MATERIALS AND METHODS}

This was a retrospective study of patients who underwent SNM from July 2013 to March 2014 at a single institution by 2 surgeons.

We excluded patients with bilateral SNM and those who did

Table 1. Patient demographics $(n=69)$

\begin{tabular}{|c|c|}
\hline Variable & Value \\
\hline Median age (yr) & 55 \\
\hline $\begin{array}{l}\text { Sex } \\
\text { Male } \\
\text { Female }\end{array}$ & $\begin{array}{r}8 \\
61\end{array}$ \\
\hline $\begin{array}{l}\text { Indications } \\
\text { Refractory overactive bladder } \\
\text { Retention } \\
\text { Pelvic pain }\end{array}$ & $\begin{array}{r}42 \\
21 \\
6\end{array}$ \\
\hline $\begin{array}{l}\text { Position } \\
\text { D0 } \\
\text { P0 } \\
\text { D1 } \\
\text { P1 } \\
\text { D2 } \\
\text { P2 } \\
\text { D3 } \\
\text { P3 }\end{array}$ & $\begin{array}{r}0 \\
4 \\
5 \\
7 \\
7 \\
11 \\
14 \\
21\end{array}$ \\
\hline $\begin{array}{l}\text { Angle } \\
0^{\circ}-30^{\circ} \\
30^{\circ}-60^{\circ} \\
60^{\circ}-90^{\circ} \\
>90^{\circ} \\
\text { Medial }\end{array}$ & $\begin{array}{r}24 \\
27 \\
9 \\
4 \\
5\end{array}$ \\
\hline $\begin{array}{l}\text { Effect of insertion } \\
\text { Working } \\
\text { Not working }\end{array}$ & $\begin{array}{l}55 \\
14\end{array}$ \\
\hline $\begin{array}{l}\text { Site } \\
\text { Right } \\
\text { Left }\end{array}$ & $\begin{array}{l}43 \\
26\end{array}$ \\
\hline
\end{tabular}

Values are presented as number of patients unless otherwise indicated. 


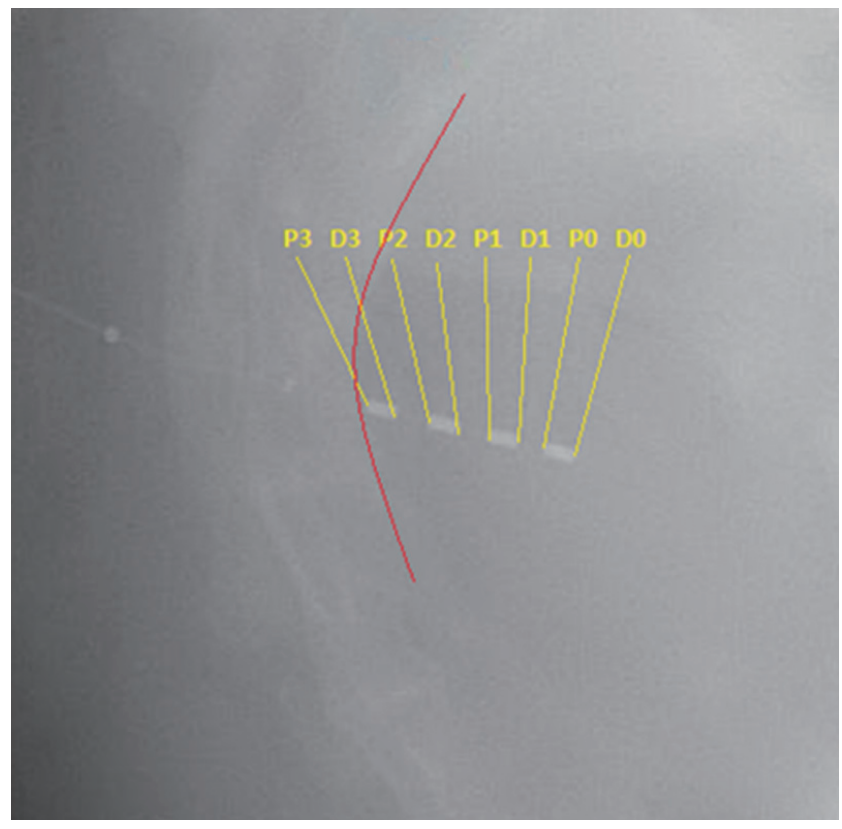

Fig. 2. Lateral view of the sacral bone with an electrode that was marked as being at P3.

not have a sacral x-ray done during the follow-up period. A total of 117 patients underwent SNM implantation at our institution during that period. Postoperative sacral x-rays were not performed in 48 patients, so they were excluded. Sixty-nine patients were included in the study. The main indications for SNM therapy were refractory OAB in 42 patients $(60.9 \%)$, chronic urinary retention (CUR) in 21 patients (30.4\%), and CPP syndrome in 6 patients (8.7\%) (Table 1$)$.

The following technique was used by the authors. The procedure was performed under general anesthesia. The anesthesiologist was typically able to avoid any long-acting muscle relaxants, which may impair sacral nerve stimulation or visualization of their motor response (bellows/toe). The C-arm of the fluoroscope was used to facilitate placement of the quadripolar permanent lead, using a curved stylet. Once it was inserted into the foramen, using the specialized foramen needle, followed by the guide wire and foramen dilator, it was tested by bipolar stimulation for a response (external pulse generator, PW 210, rate 14 , amplitude $1-10$ volts) in all 4 positions $(0,1,2$, and 3$)$. The dilator sheath was then inserted under fluoroscopic guidance. During lead insertion, in order to confirm the proper positioning, the electrode's radio-opaque marker on the inner surface of the sacrum at P2, D3, and P3 was adjusted based on the motor response (bellows/toe).

We identified the position of electrodes on plain $\mathrm{x}$-ray films

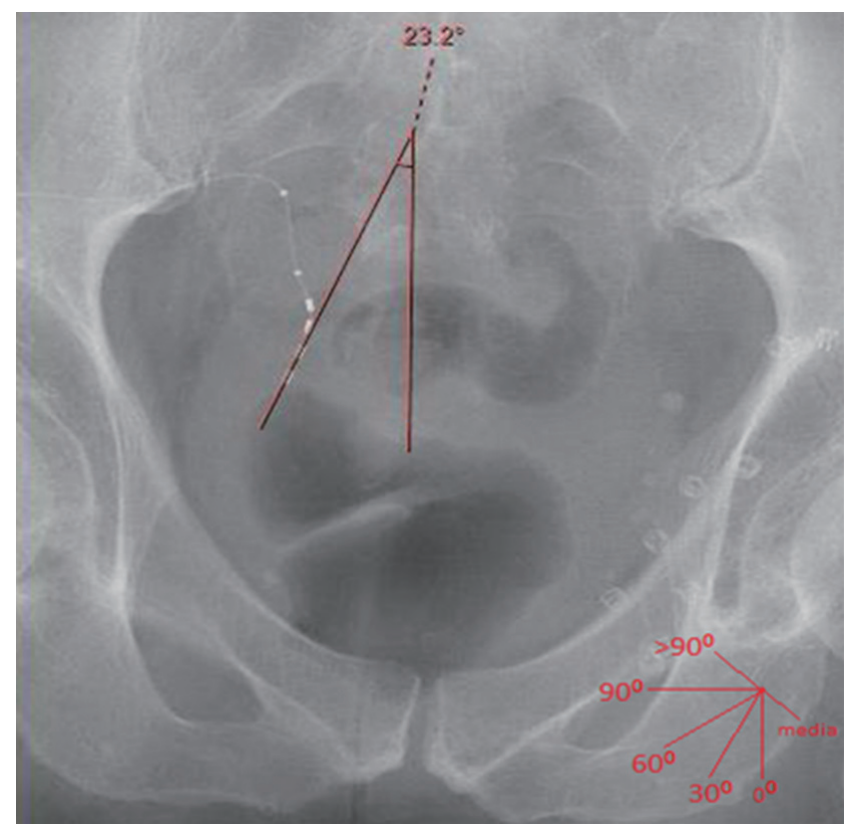

Fig. 3. Anteroposterior view. The angle is $23^{\circ}$ in this example.

in 69 patients during their postoperative follow-up. Electrodes were assessed in relation to the sacral bone in the anteroposterior and lateral views. In the lateral view, we determined the relation of the radio-opaque marker of the electrodes to the inner surface of the sacrum (P3, D3, P2, D2, P1, D1, P0, and D0) (Fig. $2)$. In the anteroposterior view, the angle between a line through the spinous process shadow and the electrode was measured $\left(0^{\circ}-30^{\circ}, 30^{\circ}-60^{\circ}, 60^{\circ}-90^{\circ},>90^{\circ}\right.$, or medial) (Fig. 3).

\section{RESULTS}

Between July 2013 to March 2014, 117 patients received SNM implantation at Toronto Western Hospital by 2 surgeons. Postoperative sacral x-rays were unavailable for 48 patients, so they were excluded. Data from 69 patients were analyzed. Forty-two patients (60.9\%) had refractory OAB, 21 (30.4\%) had CUR, and $6(8.7 \%)$ had CPP syndrome and lower urinary symptoms.

The median age was 55 years (range, $30-87$ years). Sixty-one of the patients $(88.4 \%)$ were female patients, and 8 (11.6\%) were male patients. The electrode was implanted in the right S3 (sacral foramen number 3 ) in 43 patients and in the left S3 in 26 patients (Table 1).

The patient's response and satisfaction were evaluated based on a voiding diary on the last visit to our clinic. The median follow-up was 18 months (range, 6-27 months). 
Table 2. Effects of insertion according to indication, electrode position, and angle

\begin{tabular}{lcc}
\hline Variable & Satisfied with SNM & Dissatisfied with SNM \\
\hline Indication for therapy & & 5 \\
Refractory OAB & 37 & 9 \\
Retention & 12 & 0 \\
Pelvic pain & 6 & \\
Position & & 0 \\
D0 & 0 & 0 \\
P0 & 4 & 1 \\
D1 & 4 & 2 \\
P1 & 5 & 0 \\
D2 & 7 & 3 \\
P2 & 8 & 3 \\
D3 & 11 & 5 \\
P3 & 16 & \\
Angle & & 4 \\
$0^{\circ}-30^{\circ}$ & 20 & 5 \\
$30^{\circ}-60^{\circ}$ & 22 & 3 \\
$60^{\circ}-90^{\circ}$ & 6 & 0 \\
$>90^{\circ}$ & 4 & 2 \\
Medial & 3 &
\end{tabular}

Values are presented as number of patients.

SNM, sacral neuromodulation; OAB, overactive bladder.

Table 3. Univariate analysis, showing no significant correlation between sacral neuromodulation response and electrode position or angle

\begin{tabular}{lcc}
\hline Factor & Correlation coefficient & Significance \\
\hline Age & -0.012 & 0.925 \\
Sex & -0.380 & 0.001 \\
Indication & 0.045 & 0.715 \\
Position & 0.048 & 0.694 \\
Angle & 0.105 & 0.392 \\
Site & -0.020 & 0.867 \\
\hline
\end{tabular}

Overall, 55 patients (79.7\%) were satisfied with the SNM and no further treatment was needed (e.g., an anticholinergic, $\beta 3$ agonist, Botox injection, or lead revision). Fourteen patients (20.3\%) needed further treatment to control their symptoms. Of the 42 patients with refractory OAB, 37 (88.1\%) were satisfied with the treatment. Of the 21 patients with CUR, 12 (57.1\%) were satisfied with the result and were not using a catheter. All 6 of the patients with pelvic pain with lower urinary tract symptoms (100\%) were satisfied (Table 2).

Of the patients with an electrode position of $0^{\circ}-30^{\circ}$ in the anteroposterior view, 20 were satisfied and 4 were dissatisfied, and the corresponding values for the electrode positions of

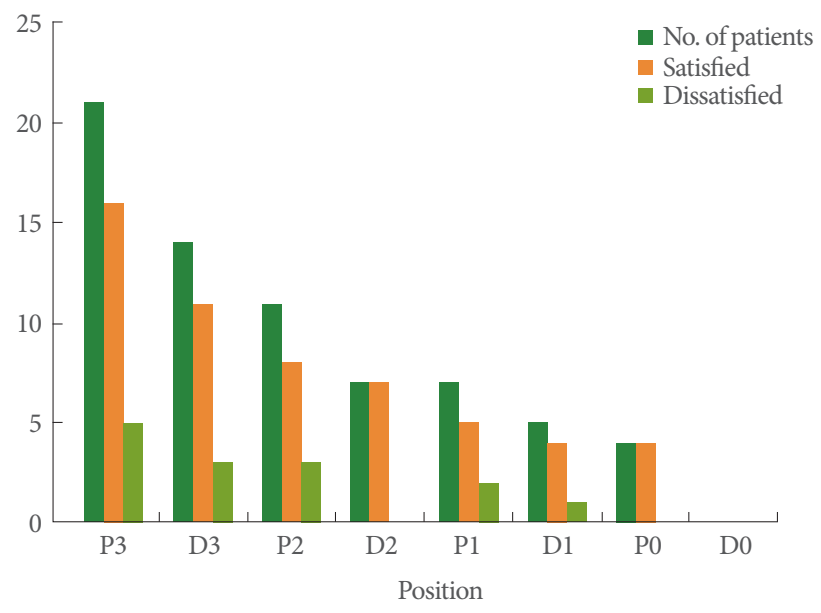

Fig. 4. The number of satisfied and dissatisfied patients according to the electrode position on lateral sacral x-rays. Despite the trend favoring P3, D3, and P2, the differences were not statistically significant.

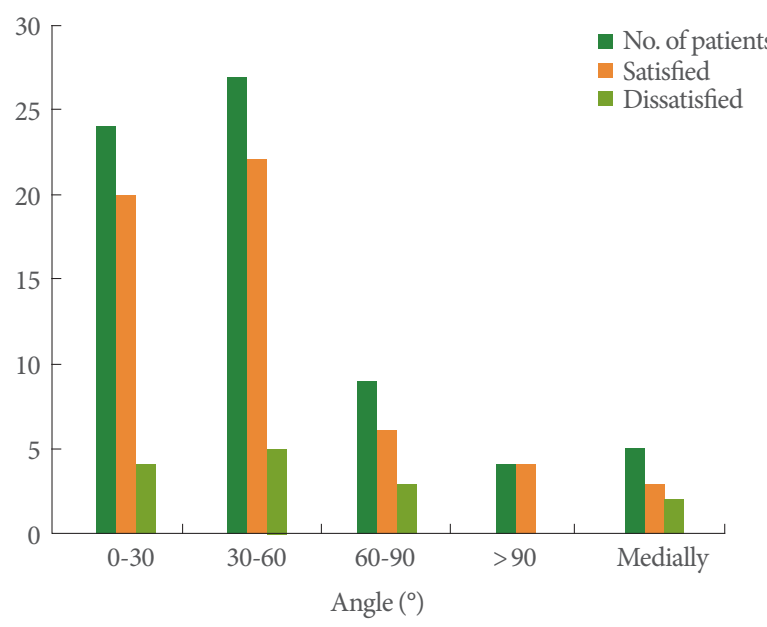

Fig. 5. The number of satisfied and dissatisfied patients according to the electrode position on anteroposterior sacral $\mathrm{x}$-rays. Despite the trend favoring $0^{\circ}-30^{\circ}$ and $30^{\circ}-60^{\circ}$, the differences were not statistically significant.

$>30^{\circ}-60^{\circ},>60^{\circ}-90^{\circ},>90^{\circ}$, and medial were 22 satisfied and 5 dissatisfied, 6 satisfied and 3 dissatisfied, 4 satisfied and 0 dissatisfied, and 3 satisfied and 2 dissatisfied, respectively. No patients had an electrode position of D0 in the lateral view. Of those with an electrode position of $\mathrm{P} 0,4$ were satisfied and 0 were dissatisfied. The corresponding values for the positions of D1, P1, D2, P2, D3, and P3 were 4 satisfied and 1 dissatisfied, 5 satisfied and 2 dissatisfied, 7 satisfied and 0 dissatisfied, 8 satisfied and 3 dissatisfied, 11 satisfied and 3 dissatisfied, and 16 satisfied and 5 dissatisfied, respectively (Table 2). 
Table 4. Dummy regression analysis using response to implantation as the dependent outcome variable did not show any significance for any of the predictors

\begin{tabular}{lcccc}
\hline Predictor & $\begin{array}{c}\text { B coefficient } \\
\text { (intercept) }\end{array}$ & SE & Significance & Exp (B) \\
\hline Age & 0.283 & 0.292 & 0.332 & 1.327 \\
Sex & -2.960 & 0.957 & 0.002 & 0.052 \\
Indication & -0.154 & 0.428 & 0.719 & 0.857 \\
Position & 0.080 & 0.176 & 0.651 & 1.083 \\
Angle & 0.566 & 0.301 & 0.060 & 1.762 \\
Site & -0.140 & 0.729 & 0.848 & 0.870 \\
\hline
\end{tabular}

SE, standard error.

Univariate analysis did not show any correlation between SNM response and electrode position or angle (Table 3, Figs. 4, 5). Dummy regression analysis using response to implantation as the dependent outcome variable did not show any significance for any of the predictors (Table 4).

\section{DISCUSSION}

Various treatment options are available for OAB, including lifestyle and behavioral changes, such as pelvic floor strengthening, bladder retraining, and management of daily fluid intake [7,9].

The pharmacological treatments used to treat OAB include anticholinergic (antimuscarinic) agents, tricyclic antidepressants, desmopressin, $\beta 3$-adrenergic receptor agonists, and intravesical Botox (Allergan Inc., Irvine, CA, USA), the latter 2 of which were most recently introduced [10].

For those individuals who are refractory to medications, intravesical botulinum toxin injections and SNM have shown significant positive effects [11].

SNM is safe and effective in $\mathrm{OAB}$ patients, with a success rate of $50 \%-90 \%$ [12-16]. SNM improved the quality of life in $86 \%$ of patients [12].

The relative simplicity of the technique, as well as the low patient morbidity associated with proper selection, makes SNM an attractive therapeutic alternative to cystectomy and urinary diversion [16]. However, SNM therapy has been hindered by a modestly high rate of complications requiring surgical revision of the neurostimulator package [19]. Siegel et al. [7] summarized the reported efficacy and complications pooled from different studies with identical protocols, devices, efficacy results, and safety profiles. Of the 914 test stimulation procedures performed in 581 patients, 181 adverse events occurred in 166 of procedures (18.2\% of the 914 procedures). Most complications were related to lead migration (108 events, $11.8 \%$ of procedures). Technical problems and pain represented $2.6 \%$ and $2.1 \%$ of the adverse events. Among the 219 patients who underwent implantation of the InterStim (Medtronic Inc., Minneapolis, MN, USA) system (lead and generator), pain at the neurostimulator site was the most commonly observed adverse effect at 12 months (15.3\%). The main indication for revision was altered stimulation with deterioration of the symptoms (53\%). Most of these patients reported a fall just before the altered stimulation [16]. In newer reports, the overall safety profile of InterStim has been found to be excellent, with estimated revision rates of $3 \%-16 \%$, often due to infection or lack of efficacy [20].

In an elegant study, Jacobs et al. [18] reported certain technical improvements during the implantation of the electrode lead. They showed that the use of a curved stylet instead of a straight stylet increased the battery lifespan because of proper alignment of the electrode closer to the sacral nerve. Using this technique, a lower voltage setting was needed to stimulate the sacral nerve to achieve the proper response.

In this study, we aimed to identify whether the radiographic electrode position was correlated with long-term efficacy of SNM therapy. The angle in the anteroposterior view was $0^{\circ}-60^{\circ}$ in 51 of the 69 patients (74\%). The position of the electrode on the lateral view at the most proximal radio-opaque mark from the inner surface of the sacral bone was 3D or 3P in 35 of the 69 patients $(50.7 \%)$.

Dummy regression analysis using response to implantation as the dependent outcome variable did not show any significance for any of the predictors.

We found that the position of the electrode on follow-up anteroposterior and lateral views of sacral $\mathrm{x}$-rays did not show any relationship with the efficacy of SNM during long-term followup. Despite this finding, we still emphasize the important role of good technique and proper placement of the electrodes intraoperatively, which will, in the majority of cases, result in positive outcomes for our patients.

\section{REFERENCES}

1. Schmidt RA, Senn E, Tanagho EA. Functional evaluation of sacral nerve root integrity. Report of a technique. Urology 1990;35:388-92.

2. Noblett KL, Cadish LA. Sacral nerve stimulation for the treatment of refractory voiding and bowel dysfunction. Am J Obstet Gynecol 
2014;210:99-106.

3. van Kerrebroeck PE, van Voskuilen AC, Heesakkers JP, Lycklama á Nijholt AA, Siegel S, Jonas U, et al. Results of sacral neuromodulation therapy for urinary voiding dysfunction: outcomes of a prospective, worldwide clinical study. J Urol 2007;178:2029-34.

4. Jonas U, Fowler CJ, Chancellor MB, Elhilali MM, Fall M, Gajewski $\mathrm{JB}$, et al. Efficacy of sacral nerve stimulation for urinary retention: results 18 months after implantation. J Urol 2001;165:15-9.

5. Hunter C, Davé N, Diwan S, Deer T. Neuromodulation of pelvic visceral pain: review of the literature and case series of potential novel targets for treatment. Pain Pract 2013;13:3-17.

6. Corcos J, Schick E. Prevalence of overactive bladder and incontinence in Canada. Can J Urol 2004;11:2278-84.

7. Siegel SW, Catanzaro F, Dijkema HE, Elhilali MM, Fowler CJ, Gajewski JB, et al. Long-term results of a multicenter study on sacral nerve stimulation for treatment of urinary urge incontinence, urgency-frequency, and retention. Urology 2000;56(6 Suppl 1):87-91.

8. Chapple CR, Gormley EA. Developments in pharmacological therapy for the overactive bladder. BJU Int 2006;98 Suppl 1:78-87.

9. Andersson KE, Chapple C, Wein A. The basis for drug treatment of the overactive bladder. World J Urol 2001;19:294-8.

10. Jayarajan J, Radomski SB. Pharmacotherapy of overactive bladder in adults: a review of efficacy, tolerability, and quality of life. Res Rep Urol 2013;6:1-16.

11. Hassouna MM, Sadri H. Economic evaluation of sacral neuromodulation in overactive bladder: A Canadian perspective. Can Urol Assoc J 2015;9:242-7.

12. Siegel S, Noblett K, Mangel J, Griebling TL, Sutherland SE, Bird ET, et al. Results of a prospective, randomized, multicenter study evaluating sacral neuromodulation with InterStim therapy compared to standard medical therapy at 6-months in subjects with mild symptoms of overactive bladder. Neurourol Urodyn 2015;34:224-30.

13. Dijkema HE, Weil EH, Mijs PT, Janknegt RA. Neuromodulation of sacral nerves for incontinence and voiding dysfunctions. Clinical results and complications. Eur Urol 1993;24:72-6.

14. Elabbady AA, Hassouna MM, Elhilali MM. Neural stimulation for chronic voiding dysfunctions. J Urol 1994;152(6 Pt 1):2076-80.

15. Thon WF, Baskin LS, Jonas U, Tanagho EA, Schmidt RA. Neuromodulation of voiding dysfunction and pelvic pain. World J Urol 1991;9:138-41.

16. Al-zahrani AA, Elzayat EA, Gajewski JB. Long-term outcome and surgical interventions after sacral neuromodulation implant for lower urinary tract symptoms: 14-year experience at 1 center. J Urol 2011;185:981-6.

17. Banakhar M, Al-Shaiji T, Hassouna M. Challenges in sacral neuromodulation. In: Carrillo-Ruiz JD, editor. Topics in neuromodulation treatment. Rijeka (Croatia): InTech; 2012. p. 35-62.

18. Jacobs SA, Lane FL, Osann KE, Noblett KL. Randomized prospective crossover study of interstim lead wire placement with curved versus straight stylet. Neurourol Urodyn 2014;33:488-92.

19. Das AK, White MD, Longhurst PA. Sacral nerve stimulation for the management of voiding dysfunction. Rev Urol 2000;2:43-60.

20. Siddiqui NY, Wu JM, Amundsen CL. Efficacy and adverse events of sacral nerve stimulation for overactive bladder: a systematic review. Neurourol Urodyn 2010;29 Suppl 1:S18-23. 